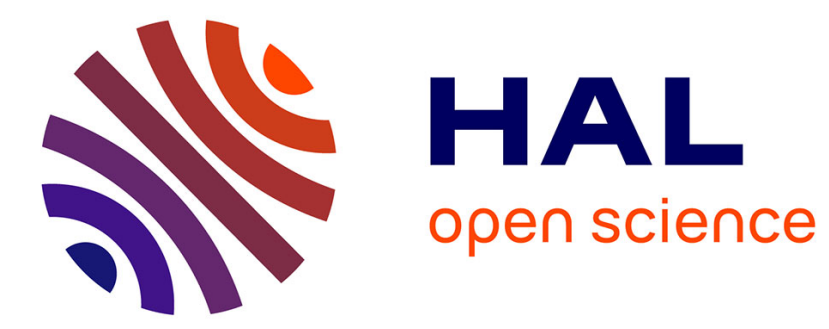

\title{
MÖSSBAUER STUDY OF AMORPHOUS FeF3, 0.4 HF IN THE MAGNETIC TRANSITION RANGE
}

\author{
J. Teillet, A. Hauet, Jean-Marc Greneche
}

\section{To cite this version:}

J. Teillet, A. Hauet, Jean-Marc Greneche. MÖSSBAUER STUDY OF AMORPHOUS FeF3, 0.4 HF IN THE MAGNETIC TRANSITION RANGE. Journal de Physique Colloques, 1988, 49 (C8), pp.C8-1095-C8-1096. 10.1051/jphyscol:19888502 . jpa-00228708

\section{HAL Id: jpa-00228708 https://hal.science/jpa-00228708}

Submitted on 1 Jan 1988

HAL is a multi-disciplinary open access archive for the deposit and dissemination of scientific research documents, whether they are published or not. The documents may come from teaching and research institutions in France or abroad, or from public or private research centers.
L'archive ouverte pluridisciplinaire HAL, est destinée au dépôt et à la diffusion de documents scientifiques de niveau recherche, publiés ou non, émanant des établissements d'enseignement et de recherche français ou étrangers, des laboratoires publics ou privés. 


\title{
MÖSSBAUER STUDY OF AMORPHOUS FeF $_{3}, 0.4$ HF IN THE MAGNETIC TRANSITION RANGE
}

\author{
J. Teillet $\left({ }^{1}\right)$, A. Hauet $\left({ }^{1}\right)$ and J. M. Greneche $\left({ }^{2}\right)$ \\ (1) LPCM, INSA, B.P. 8, 76131 Mont-Saint-Aignan Cedex, France \\ (2) U.A. 807, Université du Maine, 72017 Le Mans Cedex, France
}

\begin{abstract}
Analysis of Mössbauer spectra by unconstrained or constrained shaped distributions of both quadrupolar splitting and hyperfine field in the magnetic transition range centered on $39 \mathrm{~K}$ shows that spectra can be interpreted from static broadened field distribution only up to $36 \mathrm{~K}$.
\end{abstract}

Recently, amorphous $\mathrm{FeF}_{3}, x \mathrm{HF}(0<x<1)$ were synthetized by a soft chemistry reaction and studied by Greneche et al. in the range $4.2-400 \mathrm{~K}[1,2]$. This compound, speromagnetic at low temperature, reveals a magnetic behaviour similar to that of a spin glass with a maximum susceptibility cusp at $T_{g}=26 \mathrm{~K}$ and a broad magnetic freezing centered near $T_{\mathrm{m}}=36 \mathrm{~K}$ evidenced by Mössbauer thermal scanning [2].

The present Mössbauer study is focused on the spin freezing (temperature range $30-50 \mathrm{~K}$ with regulation better than $0.5 \mathrm{~K}$ ). Zero field Mössbauer spectra give evidence of both paramagnetic and magnetic contributions. Analysis of spectra is complicated because of the amorphous structure of $\mathrm{FeF}_{3}$, which implies both distribution of quadrupolar splitting $P(\Delta)$ and hyperfine field $P(H)$ in the transition temperature range. These two distributions have to be separately extracted from the spectra. Spectra were first analysed by a sum of discrete quadrupolar and hyperfine field static distributions with unconstrained shape (free distributions). In spite of a satisfactory fitting, the overlapping part (in $\mathrm{mm} / \mathrm{s}$ ) of the two distributions can not be shared unambiguously between $P(\Delta)$ and $P(H)$, leading to some unphysical oscillations for the low field part of $P(H)$. To overcome this difficulty, spectra were fitted by constraining $P(H)$ to be asymmetric Gaussian shaped. For this distribution, maximum value of $H$, initial value of $P(H)$ and parameter of asymmetry are fitted parameters [3]. This method was powerful for spectra between 30 and $36 \mathrm{~K}$ where $P(H)$ is extended towards low fields. Above $36 \mathrm{~K}$, where $P(H)$ is extended towards high fields, this method did not work well due to the choosen analytical distribution which is not well adapted to extension towards high fields and unconstrained distributions were used. Some fitted spectra are in figure 1 . The isomer shift does not show any discontinuity. The paramagnetic fraction curve (Fig. 2) confirms a broad transition in the range $30-50 \mathrm{~K}$ with a transition temperature $T_{\mathrm{M}}=39 \mathrm{~K}$ (defined for $\mathrm{PF}=0.5$ ) slightly higher than the previous result ( $36 \mathrm{~K}$ ) obtained by thermal scanning on a different sample. The field distributions (Fig. 3) give ev-

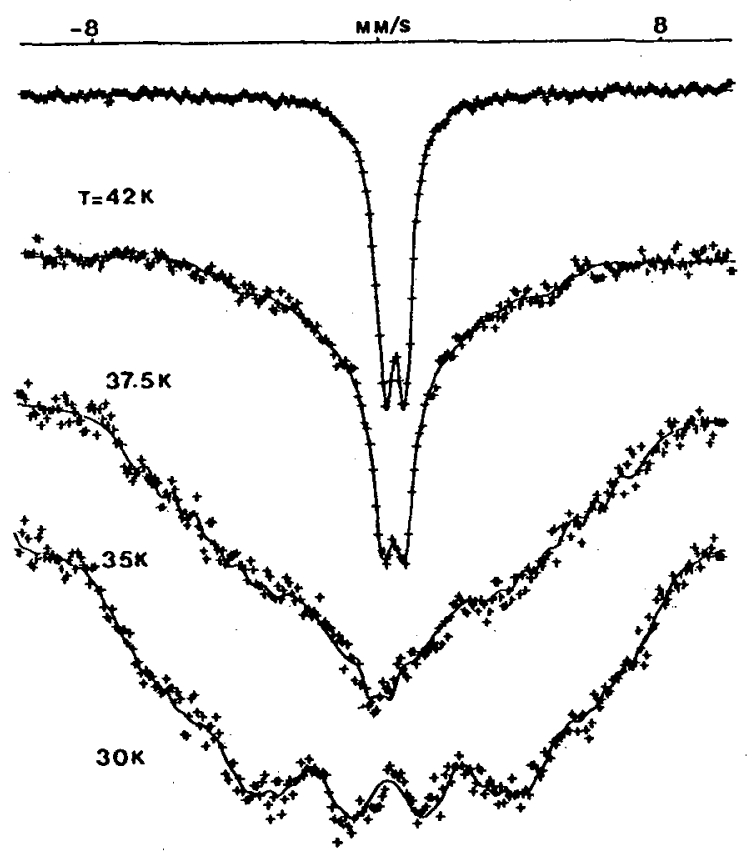

Fig. 1. - Spectra in the temperature range 30-42 K.

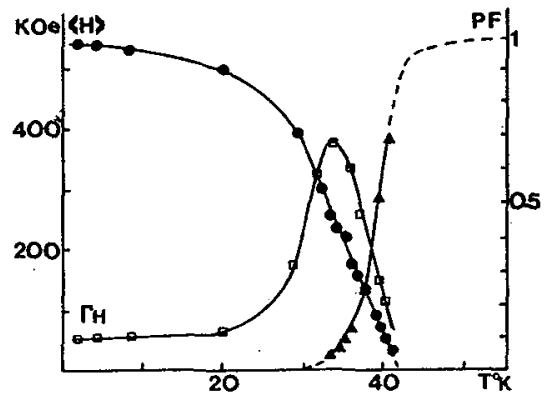

Fig. 2. - Thermal variation of average hyperfine field $\langle H\rangle$, width of the field distribution $\Gamma_{H}$ and paramagnetic fraction PF. 

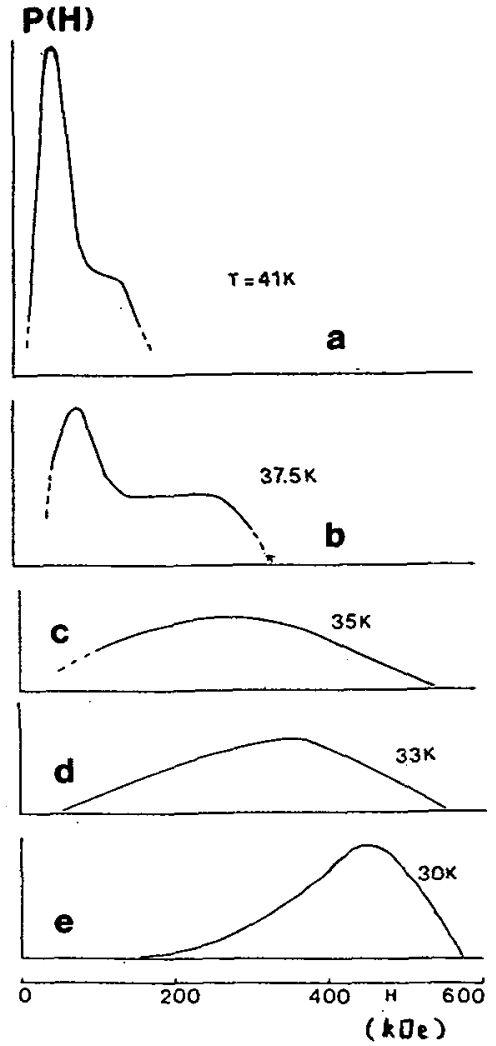

Fig. 3. - Fitted hyperfine field distributions (a, b: unconstrained shape - c, d, e: constrained shape). idence for the changing of the asymmetry in the shape about $36 \mathrm{~K}$. The average magnetic field $\left\langle H_{\mathrm{n}}\right\rangle$ is reported in figure 2 together with $\Gamma_{H}$ the width at half height of $P\left(H_{n}\right)$. The maximum of $\Gamma_{H}$ is located at $35 \mathrm{~K}=0.875 T_{\mathrm{M}}$. For high temperatures; the shape of the field distribution is unlikely, perhaps indicating that analysis of spectra requires correlated $P(\Delta)$ and $P(H)$ joint distributions. The results seem to be very similar to those on $\mathrm{Au}-3 \%$ at $\mathrm{Fe}$ [4] and $\mathrm{Rh}-5 \%$ at $\mathrm{Fe}$ [5] metallic spin-glasses. A static field distribution provides a satisfactory fit up to $36 \mathrm{~K}$, but do not excludes dynamical models. At higher temperatures, relaxation effects should be taken into account.

\section{Aknowledgments}

We would like to thank F. Varret for help in measurements and fruitfull discussions, also M. Leblanc and G. Ferey for providing us the sample.

[1] Greneche, J. M., Leblanc, M., Varret, F., Ferey, G., Hyp. Interact. 27 (1986) 317.

[2] Greneche, J. M., Varret, F., Leblanc, M., Ferey, G., Solid State Commun. 63 (1987) 435.

[3] Zemirli, M., Thesis, Université du Maine, France (1988).

[4] Meyer, C., Hartmann-Boutron, F., Gros, Y., Campbell, I. A., J. Magn. Magn. Mater. 46 (1985) 254.

[5] Meyer, C., Hartmann-Boutron, F., Gros, Y., J. Phys. France 47 (1986) 1395. 